\title{
Degradative capacities and bioaugmentation potential of an anaerobic benzene-degrading bacterium strain DN11
}

Yuki Kasai, ${ }^{1 *}$ Yumiko Kodama, ${ }^{1}$ Yoh Takahata, ${ }^{2}$ Toshihiro Hoaki ${ }^{2} \&$ Kazuya Watanabe $^{1}$

1, Marine Biotechnology Institute, 3-75-1 Heita, Kamaishi, 026-0001, Japan

2, Taisei Corporation, 344-1 Nase, Totsuka-ku, Yokohama, 245-0051, Japan

*Corresponding author

Mailing address: Marine Biotechnology Institute, 3-75-1 Heita, Kamaishi, Iwate 0260001, Japan. E-mail: yuki.kasai@mbio.jp; Phone: +81-193-26-6544; Fax: +81-193-266592

Contents

Table S1

Figures S1 and S2 
(A)

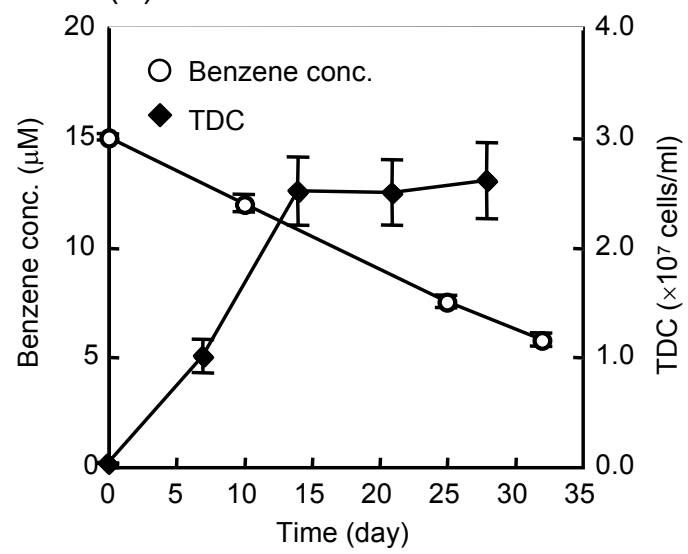

(C)

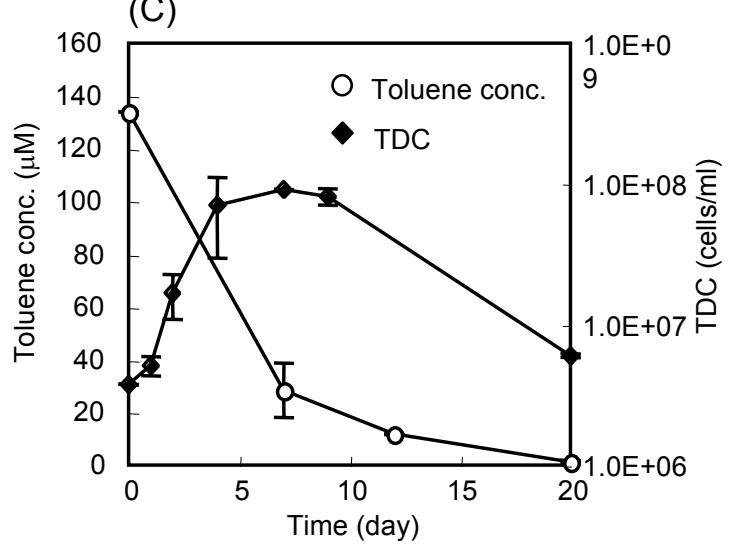

(B)
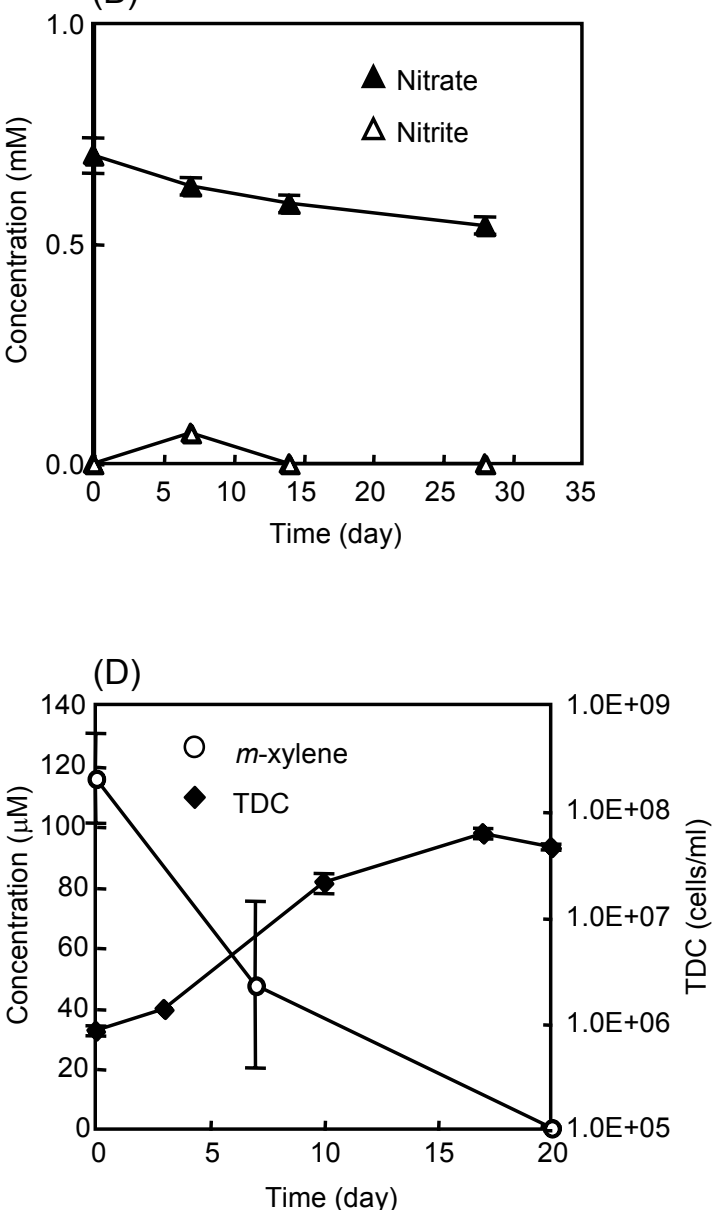

Fig. S1. Degradation of benzene (A and B), toluene (C) and $m$-xylene (D) by strain DN11. Panel $B$ shows the decrease of nitrate and the temporal occurrence of nitrite during benzene degradation. A datum point represents a mean of three incubations, while an error bar represents a $\mathrm{SD}(\mathrm{n}=3)$. 
Table S1. Evaluation of abiotic loss of benzene from sealed bottles containing benzene solutions at known concentrations.

\begin{tabular}{cccc}
\hline \multirow{2}{*}{ Bottle } & \multicolumn{2}{c}{ Concentration $(\mu \mathrm{M})^{1}$} & \multirow{2}{*}{ Loss rate $\left(\mu \mathrm{M} \mathrm{h}^{-1}\right)$} \\
\cline { 2 - 3 } & Time $0 \mathrm{~h}$ & Time $16 \mathrm{~h}$ & 0.001 \\
\hline $0.3 \mu \mathrm{M}$ & $0.301 \pm 0.012$ & $0.280 \pm 0.022$ & -0.002 \\
$0.75 \mu \mathrm{M}$ & $0.760 \pm 0.069$ & $0.790 \pm 0.023$ & 0.00 \\
$1.5 \mu \mathrm{M}$ & $1.49 \pm 0.01$ & $1.47 \pm 0.03$ & 0.00 \\
$3 \mu \mathrm{M}$ & $2.98 \pm 0.06$ & $2.91 \pm 0.09$ & 0.01 \\
$7.5 \mu \mathrm{M}$ & $7.53 \pm 0.15$ & $7.41 \pm 0.03$ & -0.0 \\
$15 \mu \mathrm{M}$ & $15.0 \pm 0.3$ & $15.3 \pm 0.1$ & \\
\hline
\end{tabular}

${ }^{1}$ Mean $\pm \operatorname{SD}(\mathrm{n}=3)$. 

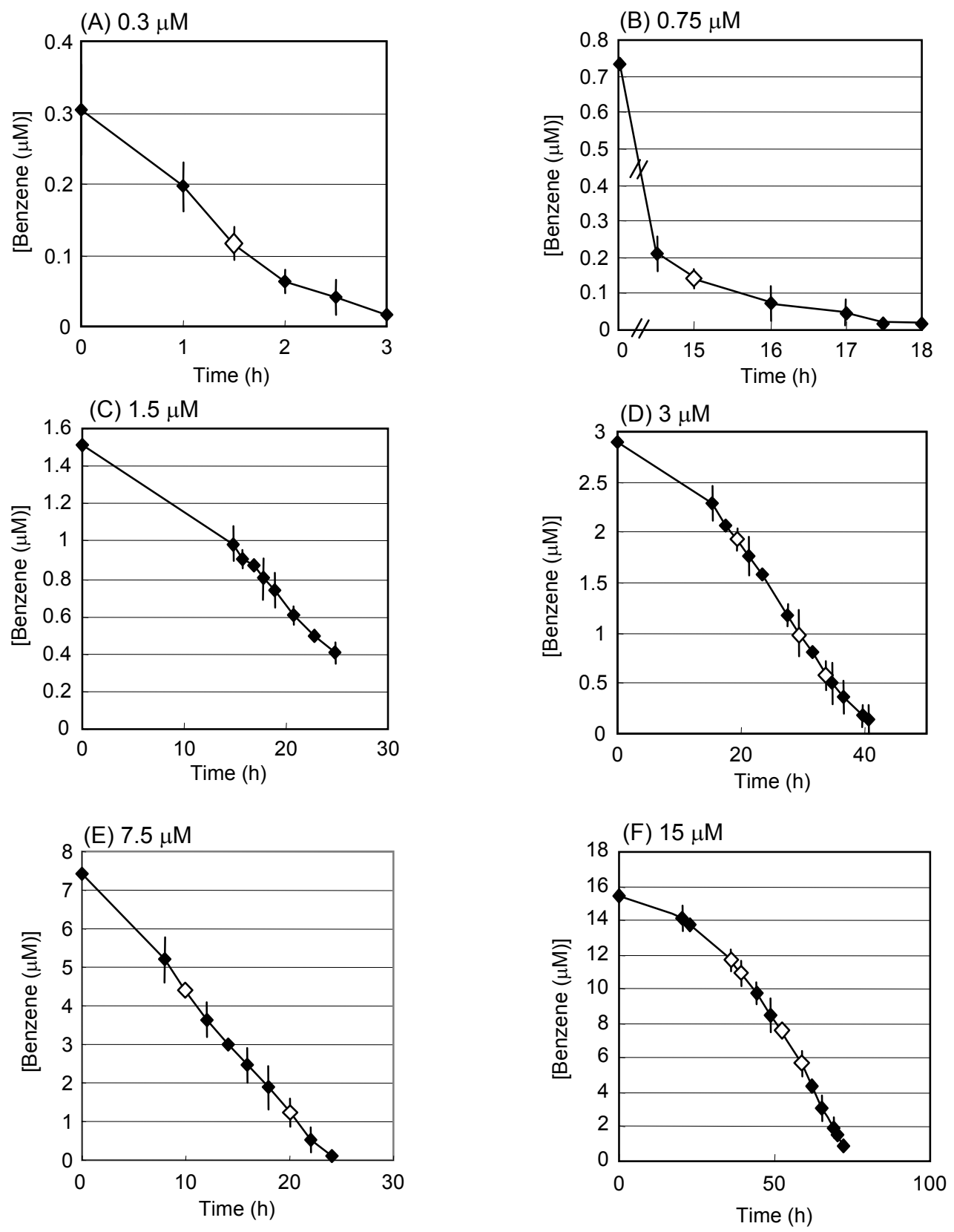

Fig. S2. Changes of benzene concentrations during biodegradation tests for determining benzene-degradation rates at different concentrations. Degradation rates at open-symbol points were estimated based on slopes around the points and used for the kinetic analysis (Fig. 3). A datum point represents a mean of three incubations, while an error bar represents an SD $(n=3)$. 